\title{
Epitaxial $\tau(\mathrm{Mn}, \mathrm{Ni}) \mathrm{Al} /(\mathrm{Al}, \mathrm{Ga}) \mathrm{As}$ heterostructures: Magnetic and magneto-optic properties
}

\author{
T. L. Cheeks, M. J. S. P. Brasil,, Jo Je Boeck,, b) J. P. Harbison, T. Sands, \\ M. Tanaka, ${ }^{\text {c) }}$ A. Scherer, and V. G. Keramidas \\ Bellcore, Red Bank, New Jersey 07701
}

\begin{abstract}
Ferromagnetic perpendicularly magnetized epitaxial thin films of $\tau(\mathrm{Mn}, \mathrm{Ni}) \mathrm{Al}$ have been successfully grown on AlAs/GaAs heterostructures by molecular beam epitaxy. We have investigated the polar Kerr rotation and magnetization of $\tau \mathrm{MnAl}$ and $(\mathrm{Mn}, \mathrm{Ni}) \mathrm{Al}$ as a function of $\mathrm{Mn}$ and Ni concentration. The largest polar Kerr rotation and remnant magnetization were obtained for $\mathrm{Mn}_{0.5} \mathrm{Al}_{0.5}$ thin films with values of $0.16^{\circ}$ and $224 \mathrm{emu} / \mathrm{cm}^{3}$, respectively. We observed that the Kerr rotation and magnetization remained constant with $\mathrm{Ni}$ additions up to about 12 at. \% and subsequently decreased with further $\mathrm{Ni}$ additions. We discuss these results and one possible method of enhancing the Kerr rotation.
\end{abstract}

\section{INTRODUCTION}

Integration of magnetic devices with optoelectronics requires compatible materials that retain both their magnetic and semiconducting properties. Recently, we have demonstrated epitaxial ferromagnetic thin films of $\tau(\mathrm{Mn}$, $\mathrm{Ni}) \mathrm{Al}$ grown on AlAs/GaAs (100) heterostructures by molecular bcam epitaxy (MBE). ${ }^{1-3}$ The films were epitaxial, single phase and have their magnetically easy $c$ axis of the tetragonal unit cell oriented normal to the (100) GaAs surface. The perpendicular magnetization of the ferromagnetic thin films was demonstrated by the extraordinary Hall effect (EHE) measurements. The measurements showed a hysteretic behavior with rectangular shaped hysteresis loops and $100 \%$ remanence. ${ }^{1}$ Preliminary measurements of the magnetic and magneto-optic properties revealed a polar Kerr rotation of $\sim 0.11^{\circ}$ and remnant magnetization $\left(M_{r}\right)$ of $-171 \mathrm{emu} / \mathrm{cm} .{ }^{3,4}$ In addition, the integrity of the underlying semiconductor and metal/ semiconductor interface was maintained, ${ }^{5}$ thereby, making device integration a possibility.

The Kerr rotation of the epitaxial films measured somewhat lower than $\mathrm{MnBi},{ }^{6}$ and the previous predicted values for Mn-based materials. ${ }^{7}$ Recently, it was reported that $\mathrm{Ni}$ additions to sputtered $\mathrm{MnAl}$ films increased the magnetization. ${ }^{8}$ Since the Kerr rotation is related in part to the magnetization, one may expect an increase in the Kerr rotation for $(\mathrm{Mn}, \mathrm{Ni}) \mathrm{Al}$ as well as $\mathrm{MnAl}$ with different $\mathrm{Mn}$ compositions. It is this issue that we address in the work reported here.

We discuss the magnetic and magneto-optic properties of epitaxial $\tau \mathrm{MnAl}$ and MnNiAl films grown on AlAs/ GaAs heterostructures. We have measured the Kerr rotation and remnant magnetization $\left(M_{r}\right)$ of $\mathrm{MnAl}$ with $\mathrm{Mn}$ concentrations of $40-60$ at. $\%$ and $\mathrm{MnAl}$ with up to 17 at. \% $\mathrm{Ni}$.

\footnotetext{
a) Present address: UNICAMP, Instituts de Fisica, Campinas SP, Brazil

bi Permanent address: IMEC, 75 Kapeldreef, B3001 Leuven, Belgium.

'On leave from Dept. Electron. Eng., The University of Tokyo, 7-3-1 Hongo, Bunkyo-ku, Tokyo 113, Japan.
}

\section{MATERIALS GROWTH AND CHARACTERIZATION}

The details of $\tau \mathrm{MnAl}$ and $\mathrm{MnNiAl}$ epitaxial growth on AlAs/GaAs heterostructures have been described in a previous publication. ${ }^{2}$ The AlAs/GaAs heterostructure was grown using standard III-V MBE growth conditions. The metal layers were grown using a template technique with a maximum temperature of $\sim 400^{\circ} \mathrm{C}$. The $\mathrm{Mn}_{x} \mathrm{Al}_{1 \ldots x}$ films were grown with the $\mathrm{Mn}$ content ranging from 0.40 $<x<0.60$ and the addition of $\mathrm{Ni}$ up to 8 at. $\%$ in $\mathrm{Mn}_{0.60-y} \mathrm{Ni}_{y} \mathrm{Al}_{0.40}$. The presence of the $\tau$ phase was verified using in situ refection high energy electron diffraction (RHEED) and ex situ x-ray diffraction. Harbison et al. ${ }^{3}$ found that for this entire range of samples, the metal films were coherently strained to the GaAs lattice with an $a_{0}$ of $0.283 \mathrm{~nm}$ and a $1.22 \mathrm{c} / \mathrm{a}$ ratio that remained unchanged up to 4 at. $\% \mathrm{Ni}$. They showed that only when $\mathrm{Ni}$ additions of 18 at. \% were applied, the $c / a$ ratio reduced to $1.09\left(a_{0}\right.$ $=0.284 \mathrm{~nm}$ ) resulting in a near cubic lattice structure. In contrast, the reported $c / a$ ratios for sputtered polycrystalline films, unconstrained to the lattice constant of the underlying substrate, decreased with much smaller $\mathrm{Ni}$ additions, i.e., 4 at. $\%{ }^{8}$ Also, the $a_{0}$ increased resulting in a more cubic rather than tetragonal lattice.

The heterostructures investigated in this study consisted of a GaAs (100) semi-insulating substrate with an undoped GaAs buffer layer grown above it. A thin $10 \mathrm{~nm}$ layer of undoped AlAs was then grown in order to leave a chemically stable aluminum-containing layer in direct contact with MnAl. To complete the structure a $10 \mathrm{~nm}$ metal layer was grown.

The spectra in Fig. 1 show the polar Kerr rotation of a $\mathrm{Mn}_{0.5} \mathrm{Al}_{0.5}$ film as a function of wavelength from 830 to 225 $\mathrm{nm}$. The rotation was measured after the samples had been poled either parallel or antiparallel to the film normal by exposure to a $0.5 \mathrm{~T}$ magnetic field. The Kerr rotation was $\sim 0.16^{\circ}$ at $800 \mathrm{~nm}$ and remained fairly constant between 500 and $800 \mathrm{~nm}$. This is important, particularly for applications, such as magneto-optic recording which require wavelengths in this range. The $0.16^{\circ}$ value is slightly lower than the $0.3^{\circ}-0.4^{\circ}$ values reported for $\mathrm{TbFeCo}$, but similar to $0.1^{\circ}-0.2^{\circ}$ reported for $\mathrm{Co} / \mathrm{Pt}$ multilayers. ${ }^{9}$

The magnetization measurements were performed us- 


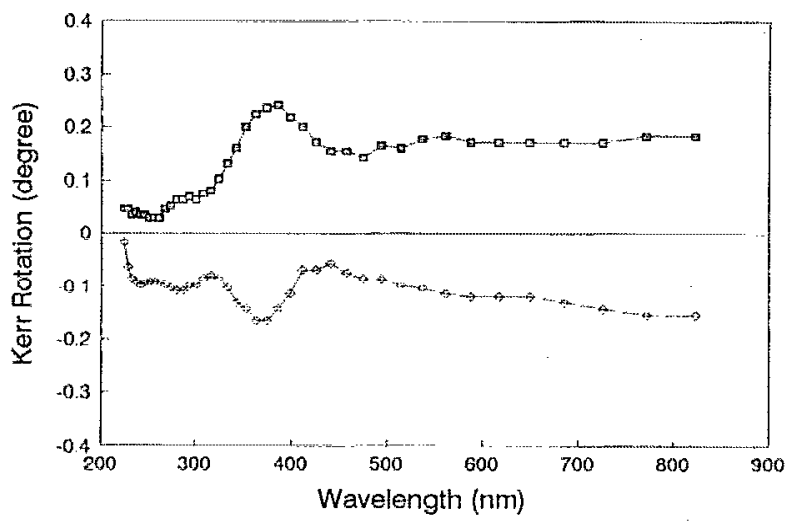

FIG. 1. Magneto-optic Kerr rotation of $\mathrm{Mn}_{0, b 0} \mathrm{Al}_{[0,40}$ as a function of wavelength.

ing a vibrating sample magnetometer with the fields directed along the easy magnetization axis. Table I summarizes the remnant magnetization $\left(M_{r}\right)$, coercivity $\left(H_{c}\right)$, and Kerr rotation of $\mathrm{Mn}_{x} \mathrm{Al}_{1-x}$ with $0.4<x<0.6$. The $M_{r}$ values reported here were not compensated with a demagnetization factor. The $\boldsymbol{M}_{\boldsymbol{r}}$ values were similar for films containing 50-60 at. \% Mn and slightly lower for the 40 at. $\%$ Mn films. The $H_{c}$ decreased with increasing Mn content. The Kerr rotation measured $0.16^{\circ}$ for $\mathrm{Mn}_{0,6} \mathrm{Al}_{0,4}$ films, while the $\mathrm{Mn}_{0.4} \mathrm{Al}_{0.6}$ films measured $0.06^{\circ}$. The reduced Kerr rotation value measured in the $\mathrm{Mn}_{0.4} \mathrm{Al}_{0.6}$ films may be due to a lower magnetization in the film. In general, the $M_{r}$ values of the epitaxial films were slightly higher than the saturation magnetization $\left(M_{s}\right)$ of $120 \mathrm{emu} / \mathrm{cm}^{3}$ obtained from sputter deposited polycrystalline $\tau \mathrm{MnAl}$ films, but lower than the bulk value of $460 \mathrm{emu} / \mathrm{cm}^{3}$.

The $\boldsymbol{M}-H$ hysteresis loops for the $\mathrm{Mn}_{x} \mathrm{Al}_{\mathrm{I}-x}$ films were nearly square with the exception of $\mathrm{Mn}_{0.40} \mathrm{Al}_{0.60}$ which showed a reduced squareness. This may be due to regions within the film with misaligned $c$-axis moments. The square hysteresis loops indicate perpendicular magnetization within the films. This is consistent with the extraordinary Hall effect measurements performed on the same films. ${ }^{3}$

The effect of $\mathrm{Ni}$ additions to $\mathrm{MnAl}$ on the remnant magnetization is shown in Fig. 2(a). The $M_{r}$ remained fairly constant at $\sim 170 \mathrm{emu} / \mathrm{cm}^{3}$ with up to 10 at. $\% \mathrm{Ni}$. With further $\mathrm{Ni}$ additions up to 17 at. $\%$, the $M_{r}$ gradually decreased down to $98 \mathrm{emu} / \mathrm{cm}^{3}$. In addition, Fig. 2(b)

TABLE I. Magnetic properties of $\tau \mathrm{MnAl}$ as a function of Mn concentration.

\begin{tabular}{lccc}
\hline \hline Sample & $\begin{array}{c}\theta_{k}(\mathrm{deg}) \\
(800 \mathrm{~nm})\end{array}$ & $\begin{array}{c}M_{r} \\
\left(\mathrm{emu} / \mathrm{cm}^{3}\right)\end{array}$ & $H_{c}(\mathrm{Oe})$ \\
\hline $\mathrm{Mn}_{0.4} \mathrm{Al}_{0.0}$ & 0.06 & 112.0 & 3918 \\
$\mathrm{Mn}_{0.5} \mathrm{Al}_{0.5}$ & 0.17 & 224.0 & 3836 \\
$\mathrm{Mn}_{0.6 .6} \mathrm{Al}_{0.4}$ & 0.16 & 214.5 & 855 \\
\hline \hline
\end{tabular}

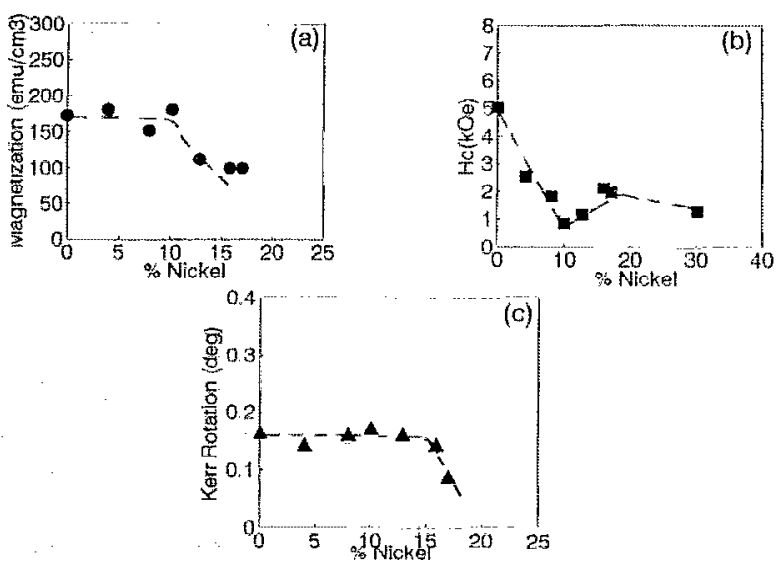

FIG. 2. The effect of $\mathrm{Ni}$ additions to $\mathrm{MnAl}$ on the (a) magnetization $\left(M_{r}\right)(\mathrm{b})$ coercivity $\left(H_{c}\right)$ and (c) polar Kerr rotation $O_{k^{*}}$ (Dotted lines added to aid the reader.)

shows the $H_{c}$ decreasing with increasing $\mathrm{Ni}$ content with a slight increase at 17 at. $\% \mathrm{Ni}$.

The $\boldsymbol{M}_{r}$ obtained for epitaxial $(\mathrm{Mn}, \mathrm{Ni})$ Al films differs from the results observed in sputtered $\mathrm{Mn}_{0.60-y} \mathrm{Ni}_{y} \mathrm{Al}_{0.40}$ films. ${ }^{8}$ In sputtered films, the $\boldsymbol{M}_{s}$ increased with $N_{i}^{\prime}$ additions up to 4 at. $\%$ and then gradually decreased with further additions. ${ }^{8}$ It was suggested that excess $\mathrm{Mn}$ atoms occupy $\mathrm{Al}$ sites and the addition of $\mathrm{Ni}$ replaces the $\mathrm{Mn}$ atoms. Reducing the excess $\mathrm{Mn}$ results in decreasing the tendency toward antiparallel coupling between $\mathrm{Mn}$ atoms located on $\mathrm{Mn}$ sites and $\mathrm{Mn}$ atoms located on $\mathrm{Al}$ sites, hence, ultimately increasing the magnetization. Also, the addition of $\mathrm{Ni}$ causes the $c / a$ ratio to decrease ( $a_{0}$ increase) which influences the $\mathrm{Mn}-\mathrm{Mn}$ coupling and the magnetization. ${ }^{8}$ However in epitaxial films, we found that the films maintained an $a_{0}$ of $0.283 \mathrm{~nm}$ which makes them coherent with the underlying AlAs/GaAs. The $c / a$ ratio, measured by $\mathrm{x}$-ray diffraction, remained the same $\left(a_{0}\right.$ remained constant) with $\mathrm{Ni}$ additions of at least 4 at. $\%$, however with 18 at. \% Ni the $c / a$ ratio reduced to $1.09\left(a_{0}\right.$ increased to $0.284 \mathrm{~nm}) .^{3}$ Compared with bulk and sputtered films, the epitaxial films may have a slightly reduced tetragonality due to elastic strain. These results suggest that if the mechanism for improved magnetization is solely related to $\mathrm{Mn}-\mathrm{Mn}$ coupling, then a constant $a_{0}$ value should result in a constant $M_{r}$. Since $a_{0}$ remains constant with up to 4 at. \% $\mathrm{Ni}$ added to the epitaxial films and coherency is maintained, the observed constant $M_{r}$ is a reasonable result. Beyond 10 at. \%, mixed phase regions or loss of coherency may account for the reduction in magnetization.

The Kerr rotation as a function of $\mathrm{Ni}$ concentration is shown in Fig. 2(c). The Kerr rotation for each sample was measured in a similar wavelength range as in Fig. 1 . The wavelength dependence of the rotation remained marginally constant in all of the samples. The values measured in Fig, 2(c) were obtained at $800 \mathrm{~nm}$ because of its technological importance. The Kerr rotation in the figure remained fairly constant at $0.16^{\circ}$ up to $\sim 13$ at. $\% \mathrm{Ni}$ and 


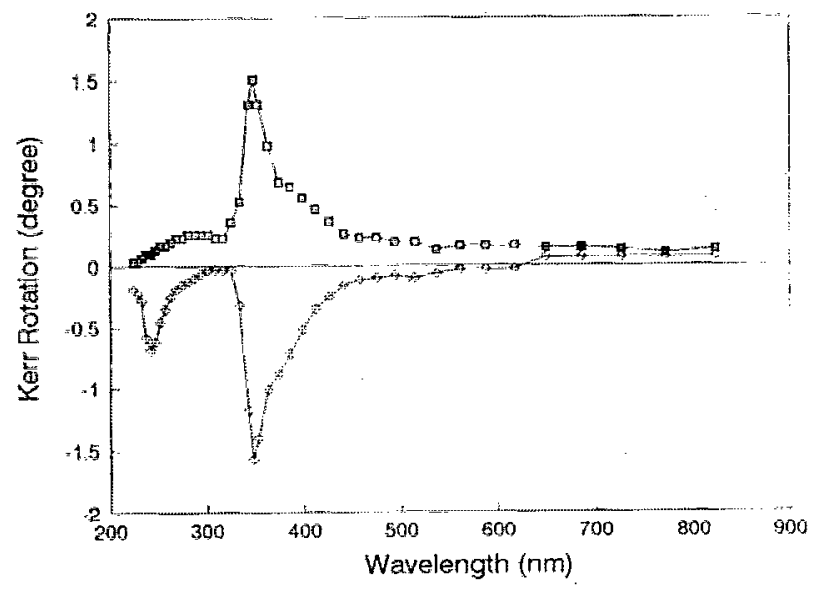

FIG. 3. Magneto-optic Kerr rotation for $150 \mathrm{~nm}$ of $\mathrm{Si}_{3} \mathrm{Ni}_{4}$ deposited on MnAl.

then gradually decreased to $\sim 0.09^{\circ}$ with further $\mathrm{Ni}$ additions. Since the squareness of the magnetization loops (i.e., the component of magnetization perpendicular to the film plane) remained square for all $\mathrm{Ni}$ compositions, one may conclude that the loop squareness makes only a small contribution. Therefore, the decrease in the Kerr rotation with increasing $\mathrm{Ni}$ content may be more strongly related to the decrease in magnetization of the films.

The Kerr rotation measured for both $\mathrm{MnAl}$ and $\mathrm{Mn}$ $\mathrm{NiAl}$ were lower than the predicted values for $\mathrm{MnAl}^{\top}$ and $\mathrm{MnBi}^{6}{ }^{6}$ This may be related to the $10 \mathrm{~nm}$ film thickness. It is expected that thicker films will have higher rotations. However, preparing thicker films remains to be a challenge to $\mathrm{MBE}$ growth. One possibility for preparing samples with higher Kerr rotations is depositing thin films of $\mathbf{S i}_{3} \mathbf{N}_{4}$ on the metal surface. A Kerr rotation of $1.5^{\circ}$, as shown in
Fig. 3 was obtained at $360 \mathrm{~nm}$ using a $150 \mathrm{~nm} \mathrm{Si}_{3} \mathrm{Ni}_{4}$ film. This enhancement was attributed to an interference effect within the multilayer structure.

In summary, we have studied the magnetic and magneto-optic properties of epitaxial $\tau \mathrm{MnAl}$ and $\mathrm{MnNiAl}$ thin films grown on AlAs/GaAs heterostructures. The films do not reveal a strong $\mathrm{Mn}$ composition dependence on the Kerr rotation and magnetization. The Kerr rotation and the magnetization remained constant with $\mathrm{Ni}$ additions up to $\sim 10-14$ at. \% and gradually decreased with further $\mathrm{Ni}$ additions. This result differs from sputtered films and may be related to the coherency that exists between the epitaxial film and the underlying GaAs heterostructure. We have discussed this issue and the possibility of using $\mathrm{Si}_{3} \mathrm{~N}_{4}$ overlayer films to enhance the Kerr rotation. The magneto-optic and magnetic properties described here may be suitable for device applications which include magnetically controllable optoelectronics.

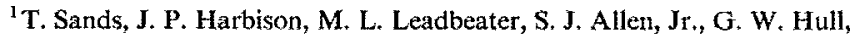
R. Ramesh, and V. G. Keramidas, Appl. Phys. Lett. 57, 2609 (1990).

${ }^{2}$ J. P. Harbison, T. Sands, R. Ramesh, L. T. Florez, B. J. Wilkens, and V. G. Keramidas, J. Cryst. Growth 111, 978 (1991).

${ }^{3}$ J. P. Harbison, T. Sands, J. De Boeck, T. L. Cheeks, P. Miceli, M. Tanaka, L. T. Florez, B. J. Wilkens, H. L. Gilchrist, and V. G. Keramidas, J. Cryst. Growth (to be published).

${ }^{4}$ T. L. Cheeks, M. J. S. P. Brasil, T. Sands, J. P. Harbison, S. J. Allen, Jr., D. E. Aspnes, and V. G. Keramidas, Appl. Phys. Lett. 60, 1393 (1992),

${ }^{5}$ T. L. Cheeks, R. E. Nahory, T. Sands, J. P. Harbison, M. J. S. P. Brasil, H. L. Gilchrist, S. A. Schwarz, M. A. Pudensi, S. J. Allen, Jr, L. T. Florez, and V. G. Keramidas, Inst. Phys. Conf. Ser. No. 120, 101 (1992).

${ }^{6}$ M. H. Kryder, J. Appl. Phys. 57, 3913 (1985).

${ }^{7}$ J. X. Shen, R, D Kirby, and D. J. Sellmyer, J. Magn. Mater. 81, 107 (1989).

${ }^{8}$ A. Morisako, N. Kohshiro, and M. Matsumoto, J. Appl. Phys. 67, 5655 (1990).

${ }^{9}$ F. J. A. M. Griedanus and W. B. Zeber, Mater. Res. Bull. XV, 31 (1990). 